\title{
Dipyridamole Stress Echocardiography and Ultrasonic Myocardial Tissue Characterization in Predicting Myocardial Ischemia, in Comparison With Dipyridamole Stress Tc-99m MIBI SPECT Myocardial Imaging
}

\author{
Osman Alper OnBASILI, ${ }^{1}$ MD, Serpil ERdogan, ${ }^{2}$ MD, Tarkan TeKten, ${ }^{1}$ MD, \\ Ceyhun CEYHAn, ${ }^{1} \mathrm{MD}$, and Yakup YUREKLI, ${ }^{2} \mathrm{MD}$
}

\section{SUMMARY}

The purpose of this study was to validate whether dipyridamole stress ultrasonic tissue characterization with cyclic variation of integrated backscatter (CVIBS) compared with dipyridamole stress echocardiography and dipyridamole stress Tc99m-MIBI SPECT myocardial perfusion scintigraphy could predict myocardial ischemia in patients with chronic coronary artery disease.

Twenty patients (16 M, $4 \mathrm{~F}$ ) who had coronary angiography for stable angina pectoris were included in the study. Mean age was $62 \pm 8$ years. The left ventricle was divided into 16 segments. Regional wall motion analysis and CVIBS measurements were obtained from 16 myocardial segments at rest and after dipyridamole $(0.84 \mathrm{mg} / \mathrm{kg})$ infusion. After 10 minutes, Tc-99m MIBI (10 mCi) was injected and SPECT myocardial imaging was performed. After 3 hours, $25 \mathrm{mCi}$ Tc-99m MIBI was reinjected and rest images were obtained.

A total of 320 ventricular wall segments were evaluated. Two hundred and six ventricular wall segments were supplied by stenotic coronary arteries and 114 segments were supplied by normal coronary arteries. Dipyridamole stress Tc-99m MIBI SPECT studies showed abnormal myocardial perfusion in 176 segments and normal perfusion in 144 segments. Transient regional wall motion abnormality was detected in 116 segments. A significant decrease in CVIBS after dipyridamole stress was detected in 184 segments. The sensitivity and specificity of dipyridamole stress echocardiography, Tc-99m MIBI SPECT, and CVIBS were $56 \%$ and $100 \%, 85 \%$ and $92 \%$, and $89 \%$ and $100 \%$, respectively, compared with the results from coronary angiography.

Dipyridamole stress ultrasonic tissue characterization with CVIBS may provide more sensitive detection of myocardial ischemia than dipyridamole stress echocardiography and may be as valuable as dipyridamole stress myocardial perfusion scintigraphy. (Jpn Heart J 2004; 45: 937-948)

Key words: Dipyridamole stress, Ultrasonic tissue characterization, Myocardial ischemia

From the ${ }^{1}$ Department of Cardiology, ${ }^{2}$ Department of Nuclear Medicine, School of Medicine, Adnan Menderes University, Aydın, Turkey.

Address for correspondence: O. Alper Onbasili, MD, Department of Cardiology, School of Medicine, Adnan Menderes University, 09100, Aydin, Turkey.

Received for publication December 15, 2003.

Revised and accepted April 30, 2004. 
$\mathrm{IN}_{\mathrm{N}}$ recent years, pharmacologic stress imaging has increasingly been employed as an alternative to exercise imaging for detection of coronary artery disease (CAD). ${ }^{1,2)}$ Intravenous infusion of dipyridamole is an acceptable alternative to exercise stress for detecting physiologically significant coronary artery stenoses using echocardiography or myocardial perfusion scintigraphy. Stress echocardiography utilizing intravenously administered dipyridamole has been used to noninvasively detect regional wall motion abnormalities in patients with CAD. An abnormal test is usually defined as one demonstrating transient asynergy of contraction that was absent or of lesser degree in the baseline examination. However, the sensitivity of dipyridamole stress echocardiography for CAD detection is somewhat less than observed with dipyridamole stress scintigraphy. ${ }^{3,4)}$ Ultrasonic tissue characterization with integrated backscatter (IBS) has been shown to be a novel approach in delineating myocardial intramural contractile performance. $\left.{ }^{5,6}\right)$ Normal myocardium exhibits cardiac cycle-dependent variation of IBS that reflects the intramural contractile performance. In animals, the cyclic variation of IBS (CVIBS) is blunted promptly by ischemia and is augmented after reperfusion. ${ }^{7,8)}$ However, the cyclic variation of integrated backscatter measured during the cardiac cycle has been shown in adults to be decreased when the myocardium is ischemic even before myocardial contraction has decreased..$^{9,10)}$

The aim of this study was to validate whether dipyridamole stress ultrasonic tissue characterization compared with dipyridamole stress echocardiography and dipyridamole stress technetium-99m methoxyisobutyl isonitrile (Tc99m-MIBI) single photon emission computerized tomography (SPECT) myocardial perfusion scintigraphy could predict myocardial ischemia in patients with chronic coronary artery disease.

\section{Methods}

Twenty patients (16 M, $4 \mathrm{~F}$ ) who had chronic stable coronary artery disease documented by coronary angiography and fulfilled all of the inclusion criteria were included in the study. Mean age was $62 \pm 8$ years. Inclusion criteria were: 1 ) no history of previous myocardial infarction, 2) angiographically demonstrated significant (> 70\%) coronary artery stenosis, and 3) a technically satisfactory acoustic window. Two patients were not included due to a bad acoustic window. All anti-ischemic drugs, such as nitrates, beta-adrenergic blocking agents, and calcium antagonists were discontinued 3 days earlier to avoid any interference with the study investigations. ACE inhibitors or diuretics were given to the patients, if necessary, to control blood pressure during the study period. The study was approved by the ethical committee of scientific research programmes of 
Adnan Menderes University School of Medicine and written informed consent was obtained from all participants.

Baseline echocardiographic examination: A Hewlett Packard SONOS 5500 (Andover, MA) echocardiograph and a multi-Hz transducer were used. All echocardiographic measurements were performed according to the recommendations of the American Society of Echocardiography. ${ }^{11)}$ The left ventricle was divided into 16 segments according to the recommendations of the American Society of Echocardiography for regional analysis of left ventricular function. ${ }^{12)}$ First, the left ventricle was divided into three equal parts perpendicular to the long axis of the heart. This generated 3 circular (basal, mid and apical) short axis slices of the left ventricle. Then, with regard to the circumferential location, the basal and mid slices were divided into 6 segments (anterior, anteroseptal, inferoseptal, inferior, inferolateral, and anterolateral) and apical slices were divided into 4 segments (anterior, septal, inferior, lateral) as shown in Figure 1.

Dipyridamole stress protocol: Dipyridamole was infused intravenously at a dose of $0.84 \mathrm{mg} / \mathrm{kg}$ of body weight over 6 minutes. Aminophylline (up to $240 \mathrm{mg}$ IV over 3 minutes) was readily at hand. The 12 lead ECG and blood pressure were recorded at 1-min intervals during the whole investigation. Nonechocardiographic end-points requiring test interruption without echocardiographic positivity were severe chest pain or significant ST segment changes (ST segment shift > $0.1 \mathrm{mV}$ from baseline at $80 \mathrm{~ms}$ after the J point in at least two contiguous leads), or both. The other test termination criteria were: 1) intolerable symptoms, 2) limiting asymptomatic side effects, including hypertension (systolic blood pressure $>220 \mathrm{mmHg}$, diastolic blood pressure > $120 \mathrm{mmHg}$ ), hypotension (relative or absolute decrease in blood pressure $>30 \mathrm{mmHg}$ ), supraventricular arrhythmias (supraventricular tachycardia or atrial fibrillation), ventricular arrhythmias (ventricular tachycardia, frequent polymorphous premature ventricular beats).

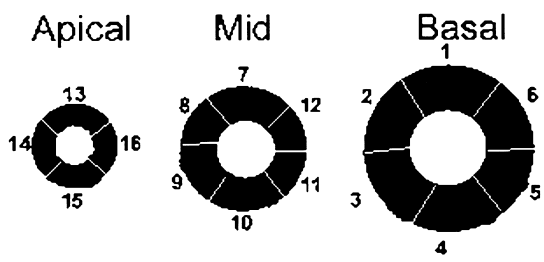

Figure 1. The left ventricle was divided into 16 segments for regional analysis of left ventricular function. It was divided into three equal parts (basal, mid and apical) perpendicular to the long axis of the heart. The basal and mid slices were divided into 6 segments (anterior, anteroseptal, inferoseptal, inferior, inferolateral, and anterolateral) and apical slices were divided into 4 segments (anterior, septal, inferior, and lateral). 
Dipyridamole stress echocardiography: Two-dimensional echocardiograms were recorded continuously during dipyridamole administration. Both analog and digital images were interpreted by two independent investigators who had no knowledge of the patient's status. For each segment, systolic wall motion was visually analyzed and noted as normal, hypokinesia, akinesia, or dyskinesia. A test result was considered positive when the systolic wall motion had deteriorated by one grade or more at dipyridamole stress.

Analysis of the magnitude of cyclic variation of integrated backscatter (CVIBS): Data from integrated backscatter analysis was obtained at rest and within 10 minutes after dipyridamole infusion. We collected the myocardial IBS data using a 2D ultrasound system (Acoustic Densitometry, SONOS 5500, Hewlett Packard, Andover, MA) equipped with a 64 element ultrasound transducer operating at a center frequency of $2.5 \mathrm{MHz}$. The amplitude of IBS was displayed in real-time in grey levels with the dynamic range of approximately $44 \mathrm{~dB}$. The transmit power was adjusted to optimize the image presentation. Time gain control was set from 70 to $100 \mathrm{db}$ to obtain the appropriate image for evaluation of the left ventricular wall. Patients who had inadequate parasternal images were excluded from the study. Lateral gain compensation and second harmonic imaging were not used in this study. For each study, 60 consecutive IBS image frames were displayed in a cine-loop of 33-ms time increments (frame rate of $30 \mathrm{~Hz}$ ) and stored on an optical disc in digital format for off-line analysis. Integrated backscatter imaging from the previously described 16 segments of 3 parasternal short-axis views were obtained before and after the dipyridamole stress test. The magnitude of IBS was quantified by placing a region of interest (ROI) within the myocardium on the frozen image. For each segment analyzed, a $21 \times 21$ pixel elliptically shaped ROI was carefully localized to avoid endo- and epicardial specular echoes. The serial changes in the magnitude of IBS within the ROI were then obtained from each frame and displayed as a curve of IBS amplitude versus time with electrocardiographic $\mathrm{R}$ wave taken as a reference (Figure 2). Three basic measurements were obtained from the integrated backscatter curve: the maximum, minimum, and maximum-minimum difference. We determined the magnitude of cyclic variation of integrated backscatter (CVIBS) in decibels as the difference between the maximal and minimal values in a cardiac cycle.

Dipyridamole stress Tc-99m MIBI SPECT myocardial perfusion scintigraphy: Dipyridamole $(0.84 \mathrm{mg} / \mathrm{kg})$ was infused intravenously for 6 minutes. After the completion of regional wall motion analysis and CVIBS measurements (within 10 minutes), Tc-99m MIBI (10 mCi) was injected and SPECT myocardial imaging was performed within 30 minutes after injection. Three hours later, $25 \mathrm{mCi}$ Tc-99m MIBI was reinjected and rest images were obtained within 30 minutes after injection. Cardiac emission tomography was performed using a single 


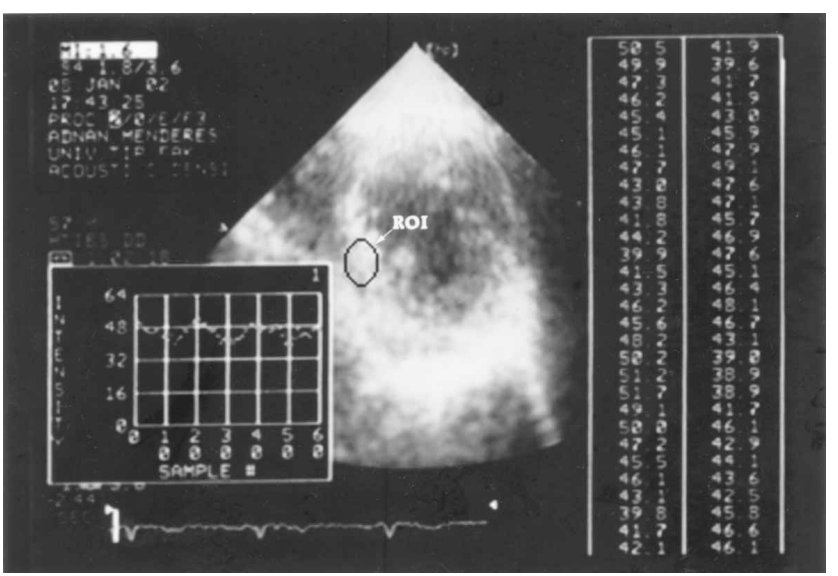

Figure 2. Measurement of CVIBS. Region of interest (ROI) is placed in the left ventricular mid inferior wall. Peak intensity of IBS occurred at end diastole, and the nadir is at end systole. CVIBS is defined as the intensity of IBS at end diastole minus the intensity at end systole, averaged over all cardiac cycles.

headed rotating gamma camera system (Siemens Medical Systems, USA) fitted with a low-energy, high resolution, parallel hole collimator. Dynamic data acquisition was performed with step and shot rotation, and images were recorded at $2.81^{\circ}$ intervals over $180^{\circ}$ orbit $\left(45^{\circ}\right.$ right anterior oblique to $45^{\circ}$ left posterior oblique) in a $64 \times 64$ matrix using a $20 \%$ energy window centered at $140 \mathrm{keV}$.

Transaxial tomographic images were reconstructed using a filtered back projection algorithm with Butterworth filter (cutoff frequency: 0.55 cycles/pixel, order 5). No correction for attenuation was performed. Short axis slices were also generated. The left ventricle was divided into 16 segments previously described in detail, allowing the clinician to match information obtained from both scintigraphic and echocardiographic analysis. Images were displayed in random order and graded using a four point score $(0=$ normal, $1=$ moderate uptake reduction, 2 = severe uptake reduction, $3=$ absent uptake). A test was considered positive when there was $\geq 1$ point score change between rest and stress images. Studies were independently reported by two experienced observers, unaware of the identity and angiographic findings for each patient.

Coronary angiography: All patients underwent coronary angiography and left ventriculography by the Judkins technique. Ventriculography was performed in the $30^{\circ}$ right anterior oblique view. Coronary arteries were selectively injected in multiple views. End-diastolic cine frames were selected for optimal stenosis visualization and magnified 5x. Eccentric stenoses were evaluated in two orthogonal views. A normal arterial segment was identified immediately proximally and dis- 
tally to the lesion and measured with an electronic calipers. The minimal stenosis diameter was also measured and severity was expressed as percent reduction of normal diameter. Significant coronary artery disease was considered $>70 \%$ reduction in luminal diameter of at least one major epicardial vessel.

Statistical analysis: All values are presented as the mean \pm standard deviation. Variations in the parameters with dipyridamole stress were evaluated with a paired-samples $t$ test. Values of $P<0.05$ were considered statistically significant. A Medcalc statistical programme (Mariakerke, Belgium) was used to calculate sensitivities, specificities, and cut-off point.

\section{RESULTS}

All patients enrolled in the study had symptomatic effort angina (14 had class II and 6 had class III according to the Canadian Cardiovascular Society (CCS) classification. Mean symptom duration was $13 \pm 11$ months. None of the patients showed clinical evidence of heart failure or gross myocardial dysfunction. Of the 20 patients with coronary artery disease, 4 exhibited a normal resting electrocardiogram, 1 had left anterior hemiblock, and 15 had different degrees of ST abnormalities. No major complications, such as severe hypotension, chest pain, dyspnea, or arrhythmia developed during or after dipyridamole infusion. Four patients had mild and transient headache, two complained of dyspnea, and one of flushing. None of these complications was severe enough to administer aminophylline.

According to the coronary angiography findings, 6 patients had one-vessel, 8 had two-vessel, and the remaining 6 had three-vessel disease. Left anterior descending coronary artery (LAD) stenosis, circumflex coronary artery (CFX) stenosis and right coronary artery (RCA) stenosis were detected in 16, 12, and 10 patients, respectively. A total of 320 ventricular wall segments were evaluated. Two hundred and six ventricular wall segments (group AA) were supplied by stenotic coronary arteries. Of the 206 ventricular wall segments, 96 segments were supplied by the LAD, 60 segments were supplied by the CFX, and 50 segments were supplied by the RCA. One hundered and fourteen segments were supplied by normal coronary arteries (group AN).

Table I. Numbers of Normal and Abnormal Myocardial Segments According to Dipyridamole Stress Echocardiography, Tc-99m MIBI SPECT, CVIBS Tests Results and Number of Segments Perfused by Normal or Abnormal Coronary Arteries According to Coronary Angiography

\begin{tabular}{lcccc}
\hline & $\begin{array}{c}\text { Dipyridamole stress } \\
\text { echocardiography }\end{array}$ & $\begin{array}{c}\text { Dipyridamole stress } \\
\text { Tc-99m MIBI SPECT }\end{array}$ & $\begin{array}{c}\text { Dipyridamole } \\
\text { stress CVIBS }\end{array}$ & $\begin{array}{c}\text { Coronary } \\
\text { angiography }\end{array}$ \\
\hline Normal segments & 204 & 144 & 136 & 114 \\
Abnormal segments & 116 & 176 & 184 & 206 \\
\hline
\end{tabular}


Resting wall motion abnormalities were detected in 17 segments, all of which were hypokinetic. However, transient regional wall motion abnormality was detected in 116 segments after dipyridamole stress testing.

Tc-99m MIBI SPECT showed abnormal myocardial perfusion in $176 \mathrm{seg}$ ments (group SA) and normal myocardial perfusion in 144 segments (group SN) after dipyridamole stress testing.

At rest, there was no significant difference in CVIBS between groups SN $(5.8 \pm 0.6 \mathrm{db})$ and SA $(6.1 \pm 0.5 \mathrm{db})$; AN (5.8 \pm 0.6$)$ and AA (5.8 \pm 0.6$)$ (Figure 3). However, in groups SA and AA, CVIBS was significantly decreased after dipyridamole stress [ $(6.1 \pm 0.5$ versus $3.8 \pm 0.6 \mathrm{db}, P<0.001)$ and $(5.8 \pm 0.6$ versus $3.7 \pm 0.4 \mathrm{db}, P<0.001$ ), respectively] (Figure 4). A significant decrease in CVIBS $(\geq 1.9 \mathrm{db})$ after dipyridamole stress was detected in 184 segments.

The dipyridamole stress echocardiography test results were normal in 90 segments although all were supplied with stenotic coronary arteries. However, dipyridamole stress Tc-99m MIBI SPECT showed abnormal perfusion in 70 of the 90 segments. Furtheremore, 74 of the 90 segments showed a significant decrease in CVIBS ( $\geq 1.9 \mathrm{db}$ ) after dipyridamole stress testing. In 16 of the 90 segments, a decrease in CVIBS after dipiyridamole stress testing was significant ( $\geq 1.9 \mathrm{db}$ ) although dipyridamole stress Tc-99m MIBI SPECT showed normal perfusion. Also, 12 of the 90 segments exhibited abnormal Tc-99m MIBI SPECT perfusion and nonsignificant changes in CVIBS values.

The sensitivity and specificity of dipyridamole stress echocardiography were $56 \%$ and $100 \%$, respectively, and of Tc-99m MIBI SPECT were $85 \%$ and $92 \%$, respectively, compared with the results from coronary angiography. When a decrease in CVIBS $\geq 1.9 \mathrm{db}$ was defined as abnormal, the sensitivity and specificity of dipyridamole stress CVIBS were $89 \%$ and $100 \%$, respectively.
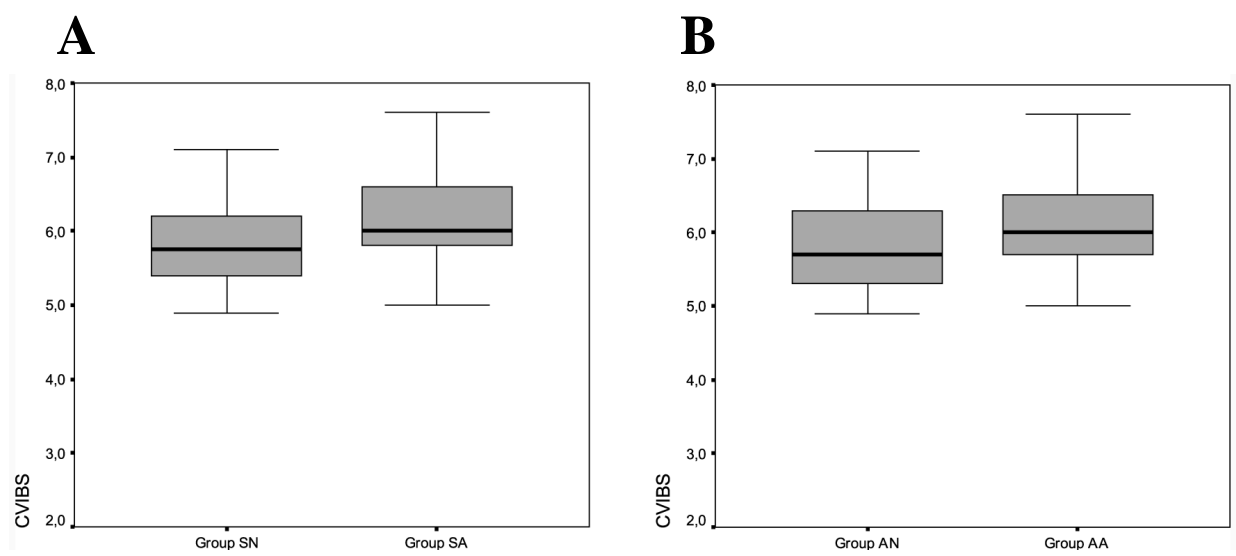

Figure 3. A: Mean CVIBS values in segments in which Tc 99m MIBI SPECT results were normal (SN) and abnormal (SA); B: mean CVIBS values in segment in which coronary angiography results were normal (AN) and abnormal (AA) before dipyridamole stress. 

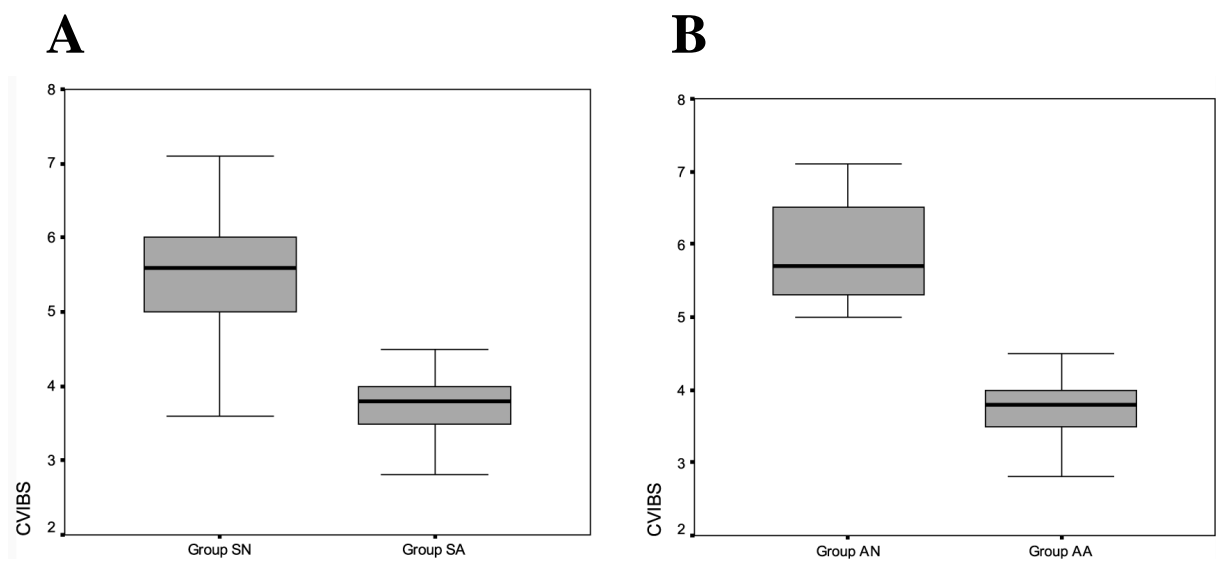

Figure 4. A: Mean CVIBS values in segments in which Tc 99m MIBI SPECT results were normal (SN) and abnormal (SA); B: mean CVIBS values in segment in which coronary angiography results were normal (AN) and abnormal (AA) after dipyridamole stress.

Table II. Sensitivities and Specificities of Dipyridamole Stress Echocardiography, Tc-99m MIBI SPECT, and CVIBS Tests According to the Coronary Angiography Results

\begin{tabular}{lccc}
\hline & $\begin{array}{c}\text { Dipyridamole stress } \\
\text { echocardiography }\end{array}$ & $\begin{array}{c}\text { Dipyridamole stress } \\
\text { Tc-99m MIBI SPECT }\end{array}$ & $\begin{array}{c}\text { Dipyridamole } \\
\text { stress CVIBS }\end{array}$ \\
\hline Sensitivity (\%) & 56 & 85 & 89 \\
Specificity (\%) & 100 & 92 & 100 \\
\hline
\end{tabular}

\section{DISCUSSION}

This study is the first, to the best of our knowledge, in which it has been shown that the combination of ultrasonic tissue characterization with CVIBS with dipyridamole stress echocardiography is better able to predict myocardial ischemia in patients with chronic coronary artery disease.

Intravenous dipyridamole is a potent and safe coronary vasodilator. It induces transmural flow redistribution via inhibition of adenosine breakdown, which causes arteriolar vasodilatation and subendocardial "steal". Therefore, this agent causes ischemia almost exclusively by altering coronary hemodynamics in the presence of critical epicardial coronary artery disease. Stress echocardiography utilizing intravenously administered dipyridamole has been used to noninvasively detect regional wall motion abnormalities caused by myocardial ischemia. It has been shown that dipyridamole stress echocardiography has lower sensitivity and higher specificity compared with dipyridamole stress myocardial perfusion scintigraphy. ${ }^{13-17)}$ Dagianti, et al and Casanova, et al showed that the 
sensitivity of dipyridamole stress echocardiography was $52 \%$ and $53 \%$, respectively. ${ }^{18,19)}$ However, the specificity of dipyridamole echocardiography has been reported to be excellent even in challenging subsets of patients in whom the rate of false-positive responses was higher with electrocardiographic or scintigraphic techniques, such as hypertensive patients. ${ }^{20)}$ In a pooled analysis of data from 11 published series, the sensitivity and specificity of dipyridamole scintigraphy for CAD detection averaged $85 \%$ and $90 \%$, respectively. ${ }^{23)}$ Our study results were compatible with those reported in the literature.

Ultrasonic tissue characterization with IBS offers a promising method for the assessment of myocardial contractile performance, viability and ischemia independent of wall motion. ${ }^{22-27)}$ Normal myocardium exhibits cardiac cycledependent variation of IBS that reflects the intramural contractile performance. The exact basis of cyclic variation integrated backscatter is not known and several mechanisms have been implicated in the changes in ultrasonic backscatter characteristics during myocardial ischemia. Interstitial and intracellular edema, alterations in the calcium and collagen contents of ischemic tissue, intramyocardial blood volume and intrinsic myocardial contractile function have been cited as possible determinants. ${ }^{24,28)}$ The magnitude of such variation has been shown to be related to the severity of ischemia. CVIBS is blunted promptly by ischemia and is augmented after reperfusion in animals and humans..$^{25,29-31)}$ Lin, et $a l^{32}$ found that the cut-off value was $2.0 \mathrm{db}$ in predicting reversible myocardial dyssynergy after revascularization. Vitale, et $a l^{33)}$ showed that the maximum-minimum difference of the integrated backscatter (CVIBS) was reduced significantly by stress in the septum $(4.6 \pm 0.9$ versus $2.7 \pm 0.8)$ (difference, $1.9 \mathrm{db}$ ). In our study, we found that the cut-off value of CVIBS was $1.9 \mathrm{db}$ in predicting myocardial ischemia by stress, which is compatible with the literature. Recovery of CVIBS after reperfusion occurs more quickly than the recovery of regional systolic wall motion not only in dogs but also in patients undergoing thrombolytic therapy for acute myocardial infarction. ${ }^{30,34)}$ However, Lin, et al showed that ultrasonic tissue characterization measures intramural contractility that may reveal subtle structural alterations in normokinetic myocardium corresponding to the ischemic response provoked by stress tests. ${ }^{32}$ They have found that the normokinetic myocardium with ischemic burden, verified by dobutamine stress echocardiography and thallium scintigraphy, showed diminished CVIBS. This may result from loss of local coordination in myocyte contraction. ${ }^{35)}$ The inhomogeneous intramural contraction could blunt the CVIBS preceding recognition of wall motion abnormalities. One of the few human studies on CVIBS changing in ischemic myocardium, by Picano, et al, ${ }^{36}$ ) has documented a rapid decrease in CVIBS during transient ischemia with coronary angioplasty although no regional wall motion abnormalities were detected. In this study, it is likely that the reduced 
magnitude of CVIBS during dipyridamole stress in segments which do not demonstrate any wall motion abnormalities can be explained more appropriately by the regional myocardial ischemia.

Clinical implications: Pharmacological stress echocardiographic testing with dipyridamole is feasible and safe. Its drug cost is very low and the imaging time is short. The stress imaging time is around 10 minutes with the high dose version $(0.84 \mathrm{mg} / \mathrm{kg})$. It is technically easier than other stress modalities. The CVIBS method has several advantages over other methods. First, it is noninvasive and simple to perform, enabling serial, long-term follow-up of patients with CAD without the use of radioisotopes. A relatively short time (3 to 5 minutes) is required to obtain cyclic variation data. Second, the present method can detect the severity of myocardial ischemia quantitatively and reliably. The sensitivity of abnormal CVIBS in the present study (89\%) was higher like as the sensitivity of Tc 99m-MIBI SPECT.

Limitations: Some limitations exist in the technique used for echocardiography and for the determination of CVIBS. The analysis is largely dependent on the image quality. Moreover, the integrated backscatter signal can be influenced by gain settings. Therefore, we set the time-gain compensation control to the identical value in each patient, from 70 to $100 \mathrm{db}$, to obtain a clear integrated backscatter image, and lateral gain control was not used. Myocardial anisotropy will complicate the assessment of integrated backscatter in those segments whose fiber orientation is not perpendicular to the interrogated ultrasonic beam. ${ }^{37}$ Another limitation is that measurement of CVIBS may be affected by the bright lines of the left septal endocardium and by intramyocardial septal specular bright echoes.

Conclusion: Ultrasonic tissue characterization with IBS can be used to detect stress inducible ischemia even in normokinetic myocardium. Dipyridamole stress CVIBS may provide more sensitive detection of myocardial ischemia than dipyridamole stress echocardiography and is as valuable as dipyridamole stress myocardial perfusion scintigraphy.

\section{REFERENCES}

1. Gould KL. Pharmacologic intervention as an alternative to exercise stress. Semin Nucl Med 1987; 17: 121-30.

2. Iskandrian AS, Heo J, Askenase A, Segal BL, Auerbach N. Dipyridamole cardiac imaging. Am Heart J 1988; 114: 432-43.

3. Picano E, Lattanzi F, Masini M, Distante A, L'Abbate A. Usefulness of the dipyridamole-exercise echocardiography test for diagnosis of coronary artery disease. Am J Cardiol 1988; 62: 67-70.

4. Margonato A, Chierchia S, Cianflone D, et al. Limitations of dipyridamole echocardiography in effort angina pectoris. Am J Cardiol 1987; 59: 225-30.

5. Miller JG, Perez JE, Sobel BE. Ultrasonic tissue characterization of myocardium. Prog Cardiovasc Dis 1985; 18: 85-110. 
6. Perez JE, Miller JG. Ultrasonic backscatter tissue characterization in cardiac diagnosis. Clin Cardiol 1991; 14: 4-9.

7. Milunski MR, Mohr GA, Wear KA, Sobel BE, Miller JG, Wickline SA. Early identification with ultrasonic integrated backscatter of viable but stunned myocardium in dogs. J Am Coll Cardiol 1989; 14: 462-71.

8. Sagar KB, Rhyne TL, Warltier DC, Pele LE, Wann LS. Intramyocardial variability in integrated backscatter: effect of coronary occlusion and reperfusion. Circulation 1987; 75: 436-43.

9. Takiuchi $\mathrm{S}$, Ito $\mathrm{H}$, Iwakura $\mathrm{K}$, et al. Ultrasonic tissue characterization predicts myocardial viability in early stage of reperfused acute myocardial infarction. Circulation 1998; 97: 356-62.

10. Goens MB, Karr SS, Martin GR. Cyclic variation of integrated ultrasound backscatter: normal and abnormal myocardial patterns in children. J Am Soc Echocardiogr 1996; 9: 616-21.

11. Henry WL, De Maria A, Gramiak R, et al. Report of the American Society of Echocardiography Committee on Nomenclature and Standards in Two-dimensional Echocardiography. Circulation 1980; 62: 212-7.

12. Cerqueira MD, Weissman NJ, Dilsizian V, et al. American Heart Association Writing Group on Myocardial Segmentation and Registration for Cardiac Imaging: Standardized myocardial segmentation and nomenclature for tomographic imaging of the heart: a statement for healthcare professionals from the cardiac imaging committee of the council on clinical cardiology of the American Heart Association. J Am Soc Echocardiogr 2002; 15: 464-8.

13. Ferrara N, Bonaduce D, Leosco D, et al. Two-dimensional echocardiographic evaluation of ventricular asynergy induced by dipyridamole: correlation with thallium scanning. Clin Cardiol 1986; 9: 437-43.

14. Parodi G, Picano E, Marcassa C, et al. High dose dipyridamole stress imaging: Comparison of sestamibi scintigraphy and 2D-echocardiography for evaluation of the extent and severity of coronary artery. Coron Artery Dis 1999; 10: 177-84.

15. Perin EC, Moore W, Blume M, Hernandez G, Dhekne R, DeCastro CM. Comparison of dipyridamole echocardiography with dipyridamole thallium scintigraphy for the diagnosis of myocardial ischemia. Clin Nucl Med 1991; 16: 417-20.

16. Santoro GM, Sciagra R, Buonamici P, et al. Head-to-head comparison of exercise stress testing, pharmacologic stress echocardiography, and perfusion tomography as first-line examination for chest pain in patients without history of coronary artery disease. J Nucl Cardiol 1998; 5: 19-27.

17. Schilaci O, Moroni C, Scopinaro F, et al. Technetium-99m sestamibi myocardial tomography based on dipyridamole echocardiography testing in hypertensive patients with chest pain. Eur J Nucl Med 1997; 7: 774-82.

18. Dagianti A, Penco M, Agati L, et al. Stress echocardiography: comparison of exercise, dipyridamole and dobutamine in detecting and predicting the extent of coronary artery disease. J Am Coll Cardiol 1995; 26: 18-25.

19. Casanova R, Patroncini A, Guidalotti PL, et al. Dose and test for dipyridamole infusion and cardiac imaging early after uncomplicated acute myocardial infarction. Am J Cardiol 1992; 70: 1402-6.

20. Cortigiani L, Paolini EA, Nannini E. Dipyridamole stress echocardiography for risk stratification in hypertensive patients with chest pain. Circulation 1998; 98: 2855-59.

21. Beller GA. Pharmacologic stress imaging. JAMA 1991; 265: 633-8.

22. Madras EI, Barzilai B, Perez JE, Miller JG. Changes in myocardial backscatter throughout the cardiac cycle. Ultrason Imaging 1983; 5: 229-9.

23. Barzilai B, Madaras EI, Sobel BE, Miller JG, Perez EJ. Effects of myocardial contraction on ultrasonic backscatter before and after ischemia. Am J Physiol 1984; 247: 478-83.

24. Wickline SA, Thomas LJ 3rd, Miller JG, Sobel BE, Perez JE. The dependence of myocardial ultrasonic integrated backscatter on contractile performance. Circulation 1985; 72: 183-92.

25. Wickline SA, Thomas LJ 3rd, Miller JG, Sobel BE, Perez JE. Sensitive detection of the effect of reperfusion on myocardium by ultrasonic tissue characterization with the integrated backscatter. Circulation 1986; 74: 389400.

26. Glueck RM, Mottley JG, Miller JG, Sobel BE, Perez JE. Effects of coronary artery occlusion and reperfusion on cardiac cycle-dependent variation of myocardial ultrasonic backscatter. Circ Res 1985; 56: 683-9.

27. Sagar KB, Pele LE, Rhyne TL, Wann LS, Waltier DC. Influence of heart rate, preload, afterload, and inotropic state on myocardial ultrasonic backscatter. Circulation 1988; 77: 478-83.

28. Mimbs JW, Bauwens D, Cohen RD, O'Donnell M, Miller JG, Sobel BE. Effects of myocardial ischemia on quantitative ultrasonic backscatter and identification of responsible determinants. Circ Res 1981; 49: 89-96. 
29. Schnittger I, Vieli A, Heiserman JE, et al. Ultrasonic tissue characterization: detection of acute myocardial ischemia in dogs. Circulation 1985; 72: 193-9.

30. Milunski MR, Mohr GA, Wear KA, Sobel BE, Miller JG, Wickline SA. Early identification with ultrasonic integrated backscatter of viable but stunned myocardium in dogs. J Am Coll Cardiol 1989; 14: 462-71.

31. Tekten T, Onbasili AO, Ceyhan C, Discigil B. Cyclic variation of myocardial integrated backscatter and myocardial wall thickness during percutaneous coronary angioplasty. Echocardiography 2003; 20: 423-8.

32. Lin LC, Ho YL, Wu CC, et al. Comparison of simultaneous dobutamine echocardiography and thallium-201 stress-reinjection single-photon emission computed tomography in predicting improvement of chronic myocardial dysfunction after revascularization. Am J Cardiol 2000; 86: 293-8.

33. Vitale DF, Bonow RO, Gerundo G, et al. Alterations in ultrasonic backscatter during exercise-induced myocardial ischemia in humans. Circulation 1995; 92: 1452-7.

34. Milunski MR, Mohr GA, Perez JE, et al. Ultrasonic tissue characterization with integrated backscatter. Acute myocardial ischemia, reperfusion, and stunned myocardium in patients. Circulation 1989; 80: 491-503.

35. Kaprielian RR, Gunning M, Dupont E, et al. Downregulation of immundetectable connexin 43 and decreased gap junction size in the pathogenesis of chronic hibernation in the human left ventricle. Circulation 1998; 97 : 651-60.

36. Picano E, Faletra F, Marini C, et al. Increased echodensity of transiently asynergic myocardium in humans: a novel echocardiographic sign of myocardial ischemia. J Am Coll Cardiol 1993; 21: 199-207.

37. Hall CS, Verdonk ED, Wickline SA, Perez JE, Miller JG. Anisotropy of the apparent frequency dependence of backscatter in formalin fixed human myocardium. J Acoust Soc Am 1997; 101: 563-8. 